\title{
Entre la Lírica Culta y la Lírica Tradicional: Los Villancicos de Sor Juana Inés de la Cruz
}

Elsa Beatriz Grillo

UNNE

\section{Resumen}

La propuesta consiste en realizar una lectura epistemológica de los Villancicos de Sor Juana Inés de la Cruz, pertenecientes a la Serie de la Asunción de 1676, desde de un marco de referencia que contemplará tres cuestiones, las características generales de ese género literario, las particularidades de la lírica de la ortodoxia cristiana y el tratamiento que da la autora a una figura femenina, la de la Virgen María.

¿Se corresponden con la lírica tradicional? ¿Son adaptaciones a lo divino de poemas profanos? ¿Pretenden cumplir funciones didáctica y dogmática-política? ¿Postulan la igualdad de derechos entre mujeres y hombres?

\section{Introducción}

En este trabajo se realizará una lectura epistemológica de los Villancicos de Sor Juana Inés de la Cruz pertenecientes a la Serie de la Asunción de 1676, desde un marco de referencia que contemplará tres cuestiones: las características generales de ese género literario; las particularidades de la lírica de la ortodoxia cristiana y el tratamiento de una figura femenina; al respecto, se sefiala que llama la atención esto último, no sólo por ser un tema actual en un momento en que se habla mucho sobre la igualdad de la mujer con respecto del hombre, sino especialmente, por su recurrencia en toda la obra de la autora.

La inquietud por la lectura de esos villancicos surge como una primera respuesta a la hipótesis de que tendrían carácter popular, si se los concibe como pertenecientes a un género menor de amplia repercusión en el Siglo XVII Novohispano.

¿Se corresponden con la lírica tradicional? ¿Son adaptaciones a lo divino de poemas profanos? ¿Pretenden cumplir funciones didáctica y dogmática-política? ¿Postulan la igualdad de derechos entre mujeres y hombres?

Los interrogantes planteados, determinan la primera cuestión por considerar, que es la de su propia pertinencia y es por ello, que se elaborará, un marco referencial desde dónde se puedan explorar los textos. En segundo término, a partir de un corpus que se conformará con una selección de villancicos, se formalizará, su análisis desde los interrogantes señalados, para determinar si el resultado se corresponde o no, con el marco propuesto y por último, se sintetizarán las conclusiones de la lectura.

\section{Acerca del villancico}

En relación con la historia del villancico Antonio Sánchez Romeralo ${ }^{44}$ plantea, que a mediados del S. XV se despertó en Castilla, Navarra y Aragón un interés especial por las

${ }^{44}$ SANCHEZ ROMERALO, Antonio. El Villancico. Gredos. España. Páginas 50 a 54. 
canciones populares, a raíz de la influencia de la Italia renacentista (la Corte de Alfonso $\mathrm{V}$ en Nápoles) y su gusto por lo novedoso. Tanto fue así, que esa afición italiana por las canciones de los villanos llegó a Castilla en donde se consagró el nombre de villancico con el que se designó a las canciones populares.

A la vez, ese gusto se manifestó en tres corrientes de características diferentes: por una parte, surgió una lírica popularizante, la que realizaban poetas y músicos (los pastiches), cuyas canciones eran imitaciones de temas y lengua de las canciones populares; por otra, una corriente que tuvo manifestaciones paralelas dentro de la lírica cortés (el gusto por el mote o la letra como iniciación literaria),en dicho caso, de acuerdo con las prácticas poéticas establecidas, los poetas utilizaban cancioncillas sueltas, 0 estrofas de ellas y a partir de allí elaboraban sus propias producciones; por último, la tercera corriente fue la creación de una forma poética nueva del 'villancico cortés': poetas inspirados en los villancicos y su forma irregular componian nuevas formas, de acuerdo con los cánones poéticos de la lírica culta.

Señala además el autor antes citado ${ }^{45}$, que siempre que se dirime si el villancico es o no un género popular (tradicional), se está efectuando un juicio estilístico y que al hacerlo se recurre generalmente a la lengua que se utiliza y a los aspectos relacionados con el estilo; y que si bien, él no cree en la 'pureza' popular, ni en la posibilidad de detectar villancicos auténticamente populares frente a sus imitaciones, sí cree en la existencia de un 'estilo popular' y en la necesidad de explicar en qué consiste tal estilo, y que para ello, es preciso partir de la definición de sus características predominantes y de los rasgos que no son, o no pueden ser considerados populares.

Al respecto expone también, que en los casos en que los cantores de la lírica popular alteraban las letras de las canciones se sentian creadores de otras nuevas, aún sabiendo que el origen de sus producciones eran otras distintas y anteriores; y que debido a que ese proceso era permanente, lo que se transmitía no eran las canciones, sino los temas y las fórmulas genéricas que fueron constituyendo un estilo. Y que es por es razón, que más que transformar una pieza en otra, la tradición fue generando procesos colectivos de creación de estilos. Estilos que hacen que las canciones se consideren tradicionales (estilísticamente tradicionales). En síntesis, lo que Sánchez Romeralo expresa es que la canción tradicional es por una parte, la que la tradición transforma y por otra, la creada dentro de una tradición estilística temática. Dice este autor: "(...) la tradición de la poesía popular, una tradición capaz de recibir elementos procedentes de la tradición culta, pero siempre que se den estas circunstancias: $1^{\circ}$ ) Que esos elementos resulten asimilables por la gran masa heredera y usuaria de la tradición popular. (...), el pueblo sólo puede convertir en popular algo que esté muy cerca ya de él. Por eso, una gran mayoría de las glosas y los villancicos cultos resultan de todo punto intradicionalizables. $2^{\circ}$ )Para que esa asimilación se realice, lo culto tiene que perder el propio estilo y hacerse estilísticamente popular; lo que significa tanto como perder todo aquello que lo caracteriza como culto frente a lo popular (todo lo que el pueblo no diría de esa modo); es decir que lo culto tiene que dejar de ser culto y hacerse popular." (Sánchez Romeralo, 1969: $126-127$ ). ${ }^{46}$

\footnotetext{
${ }^{45}$ Op., cit. Págs. 10 a 12.
}

${ }^{46}$ Op., cit. Págs. 126 a 127. 


\section{Sobre la lírica a lo divino}

Una cuestión apreciable para este trabajo es destacar que en algunos casos ya en el siglo XVI los villancicos eran compuestos para fines religiosos. Uno de los iniciadores de esa vía es Juan Álvarez Gato, quien endereza 'a lo espiritual y al daffo que del mundo viene'47 un cantar que decía:

Quita allá que no quiero, falso enemigo, Quita allá, que no quiero Que huelgues conmigo

-¿Quién te trajo caballero, Por esta montaña escura? - $\mathrm{Ayy}$, pastor, que mi ventura! Que huelgues conmigo

Y lo hace decir, conservando el ritmo de la seguidilla: Quita allá que no quiero, mundo enemigo,

Quita allá, que no quiero

Desde esta perspectiva, Bruce W. Wardropper sefiala, que existe una expresión que antiguamente se denominaba 'villancico, vuelta a lo divino o contraecho a lo divino', pero que la más tradicional es una expresión castellana que se compara con una fórmula alemana 'contrafactum', al que define diciendo: '(...) es una obra literaria (...) generalmente un poema lírico de corta extensión, cuyo sentido profano ha sido sustituido por otro sagrado. Se trata pues de la refundición de un texto." (Wardropper, 1958: 5- 6). ${ }^{49}$

Expone también, el autor que la forma métrica que más se divinizaba era el villancico debido a que por su origen profano, se prestaba con más facilidad a la divinización, por el hecho de que al tener un núcleo y una glosa o desarrollo en coplas se facilitaba el proceso de recreación. Y señala, que la literatura contrafactista tiene su raíz en la divinización de temas, porque mira a lo divino desde lo concreto y actual, y sugiere una manera de enfocar un misterio divino en términos mundanos y familiares. ${ }^{30}$

Por otra parte, Margit Frenk Alatorre ${ }^{51}$ dice que durante todo el Siglo de Oro dentro de los cantares folklóricos, se utilizó a los villancicos por ser canciones populares que tenían un estribillo a menudo amatorio, para darles un sentido religioso y que durante los siglos XVI y XVII se siguió encontrando desarrollos de ese tipo. Pero que dentro de la poesía religiosa fue más frecuente todavía, otra manera de utilización de la canción popular, las versiones a lo

47 WARDROPPER, Bruce W. Historia de la Poesía Lírica a lo Divino en la Cristiandad Occidental. Revista del Oriente. España. 1958. Pág.40.

${ }^{43}$ SANCHEZ ROMERALO, Antonio, Op., cit. Pág. 32.

49 WARDROPPER, Bruce W. Historia de la Poesía Lirica a lo Divino en la Cristiandad Occidental. Revista del Oriente. España. 1958. Págs.5 a 6.

${ }^{30}$ Op., cit. Pág. 325.

${ }^{31}$ FRENK ALATORRE, Margit. Estudios sobre la lírica antigua. Editorial Castalia. España. 1978. Páginas 59-60. 
divino que consistian en que los poetas escribían villancicos al tono de un cantar ya conocido $\mathrm{y}$ adoptaban su estribillo transformándolo al tema religioso.

Cita la autora, el siguiente ejemplo de vuelta a lo divino: ${ }^{52 ،}$ 'Lo que demanda/ el romero, madre, /lo que demanda/ no se lo dan." "Lo que demanda/ el primero Padre, / lo que demanda/ ya se lo dan."(Frenk Alatorre, 1978:59-60).

Margit Frenk señala además, que desde finales del siglo XV tanto músico como poetas recogieron cantares populares para elaborar otras imitaciones y dice: "Se trataba de dar un toque popular, y éste podía obtenerse con poesías hechas ex professo. (...) ¿En cuántos estribillos de la época que denotan un afán popularizante descubrimos dejos manifiestos de la poesía cortesana?" (Frenk Alatorre, 1978: 61-62). ${ }^{53}$

\section{Los villancicos de Sor Juana en el contexto de Nueva España en el Siglo XVII}

En relación con el Siglo XVII en Hispanoamérica, expresa Méndez Plancarte en su estudio preliminar del Tomo II de las Obras Completas de Sor Juana Inés de la Cruz: "Y así llegamos a la nueva etapa en que los Villancicos se organizan en 'suites' de ocho o nueve 'letras', para su intercalación musical en el Oficio Divino - según queda explicado en nuestro esbozo de la Península - .Cuando haya principido esa costumbre es un tanto incierto. Las primeras constancias que conocemos, datan de la mitad del XVII o de muy poco antes, como los anónimos Villancicos que se cantaron en la Puebla de los Ángeles en los Maitines y Misa del glorioso San Laurencio (...). Y luego en 76 en que principian los de Sor Juana, y a partir del cual año, hasta finales del siglo, sí han llegado a nosotros numerosísimos, en cadena ininterrumpida y de los más diversos temas y autores."(Méndez Plancarte, 2004:XXXV XXXVII).

Hacia 1630 se comenzó a llamar villancicos a las composiciones que se cantaban en los maitines de las fiestas religiosas; los maitines se dividían en tres nocturnos cada uno de tres salmos y los villancicos adoptaron la misma división tres nocturnos compuestos de tres letras, pero en muchas ocasiones la última letra era sustituida por el Te Deum. En México la costumbre de cantar villancicos (compuestos de tres nocturnos), en los maitines de las fiestas litúrgicas se remonta, tal como lo plantea Méndez Plancarte a la segunda mitad del siglo XVII.

Las catedrales de México, Puebla Oaxaca y otras y también, los templos mayores celebraban las grandes festividades religiosas con esos cánticos y la periodicidad de los actos religiosos, su suntuosidad y el número de fieles que asistía exigían una organización esmerada. Los villancicos eran un espectáculo y constituían ceremonias que tenían una función religiosa pero también social y política pues durante ellas, el grupo social a través de ese símbolo se reunía consigo mismo.

Es importante tener presente que en el Virreinato de Nueva España que era una sociedad heterogénea tanto por la diferencia de clases sociales como por la diversidad de pasados,

32 HOROZCO, Cancionero, p.139 en: FRENK ALATORRE, Margit. Estudios sobre la lirica antigua. Editorial Castalia. Espanfa. 1978. Páginas 59-60.

${ }^{33}$ FRENK ALATORRE, Margit. Estudios sobre la lírica antigua. Editorial Castalia. Espanta. 1978. Páginas 61-62.

${ }^{34}$ MENDEZ PLANCARTE, ALFONSO. Estudio preliminar. En: Tomo II de las Obras Completas. Villancicos y Letras Sacras. Fondo de Cultura Económica, México, 2004. Págs XXXV a XXXVII. 
creencias y razas (españoles, criollos, indios, mestizos, negros), las fiestas religiosas eran ceremonias de celebración y de participación.

Margo Glanz ${ }^{55}$ relata que en el día en que se cantaban los villancicos en Puebla, desde el año 1617 cuando se fundó el Convento Concepcionista, el Cabildo de esa ciudad juró defender como artículo de fe la inmaculada Concepción de la Virgen, que fue promovida a Patrona de la ciudad en 1619 y que a esas festividades contribuyó Sor Juana, casi cincuenta afios más tarde, cuando fue invitada a escribir villancicos para la Catedral. Dice Glanz que esas fiestas contaban con una larga tradición en el virreinato y que en ellas revivían ingredientes populares y costumbres locales (corridas de toros, juegos de canias, lanzamiento de cohetes y la imitación del habla o 'media lengua' de los grupos marginales), mezcladas con los juramentos de la defensa de la 'opinión pía' de la Inmaculada Concepción.

$Y$ cuenta respecto de los villancicos que se cantaban, que el hecho de que éstos registraran en sus letras juegos y adivinanzas, era también una manera de llamar la atención de los fieles que pertenecían, sobre todo, a las clases sociales más bajas, porque al poner en escena lo popular se dignificaba la actuación de los fieles (oficios y actividades), mediante su trasformación a lo divino. Y que fue por eso, que los villancicos tuvieron una finalidad didáctica y dogmática porque sirvieron para que el pueblo comprendiera conceptos teológicos complejos.

De igual manera, la autora Yolanda Martínez San Miguel expone ${ }^{56}$ que estudios críticos sobre los villancicos de Sor Juana, tales como el de Octavio $\mathrm{Paz}^{57}$ destacan su carácter popular y su capacidad representativa de las voces marginadas de la sociedad colonial.

\section{La correspondencia de los villancicos de Sor Juana con la Lírica Tradicional}

Recurriendo nuevamente a Margit Frenk, para rescatar otro dato, que no deja de ser importante, se cita lo siguiente: "Los poemas se componían con arreglo a determinadas tradiciones preestablecidas, a ciertas 'maneras de poetizar' ya consagradas. Cada 'tradición' o 'escuela' poética tenía su repertorio de formas métricas, de temas y motivos, de imágenes y metáforas, de recursos estilísticos. Cada nuevo poema constitufa una recreación a base de elementos conocidos." (Frenk, 1989:50). ${ }^{58}$

Por ende, se piensa que si bien es indudable que Sor Juana se adhirió a las escuelas poéticas de su tiempo y que la métrica, los recursos, las imágenes y los temas que utilizó fueron recreaciones de modelos anteriores y que más aún, tal como lo afirma Bruce Wardropper varios de ellos, como lo prueba la tradición, son adaptaciones a lo divino de poemas profanos, los escribió respetando el 'estilo popular', debido a las razones que merecen ser indagadas.

Según Margit Frenk, las características formales de los villancicos, sin soslayar las modificaciones que se produjeron en el siglo XVII, son las siguientes: "Consta de una estrofa

${ }^{55}$ GLANZ, Margo. El discurso religioso y sus políticas. Fondo de Cultura Económica. México. 1995. Págs. 509 a 511.

${ }^{36}$ MARTINEZ SAN MIGUEL, Yolanda. Saberes Americanos: la constitución de una subjetividad colonial en los villancicos de Sor Juana. www.cervantesvirtual.com.

${ }^{37}$ PAZ, Octavio. Sor Juana Inés de la Cruz o Las Trampas de la Fe. Fondo de Cultura Económica. México. 1992. Página 420.

${ }_{38}$ FRENK, Margit (ed). Villancicos, romances, ensaladas y otras canciones devotas de Fernán González Eslava. El Colegio de México. México.1989.Página 50. 
breve - cabeza, estribillo - y varias estrofas - coplas, pies - que desarrollan el tema de la estrofita inicial y que se dividen cada una en dos partes: la primera se llama mudanza, porque en cada estrofa cambia de rimas; la segunda, llamada vuelta, tiene el mismo número de versos que la cabeza y repite sus rimas, a veces enlazándolas con una rima de la mudanza; al final de la vuelta reaparecen textualmente los últimos versos - generalmente los dos últimos - de la cabeza. La estructura musical del villancico corresponde a su juego de rimas: hay una música destinada a la cabeza y a las vueltas de las estrofas y otra - frecuentemente emparentada con aquélla - para las mudanzas." (Frenk, 1989:142). ${ }^{59}$

\section{La adaptación a lo divino de y la igualdad entre mujeres y hombres}

La serie de Villancicos dedicados a la Asunción de 1676 cantados en la catedral Metropolitana de la ciudad de México, en honor de María Santísima Madre de Dios, en su Asunción Triunfante, se inicia con el Villancico 217 (Primero Nocturno - Villancico I), ${ }^{60}$ su contenido se refiere a una competencia entre el Cielo y la Tierra, para ver cuál de ambos obtuvo el mayor favor divino; el público, los fieles creyentes que participaban de las fiestas religiosas, debían definir cuál de los jugadores era el triunfador. Dice este villancica:

"El Cielo y Tierra este día

compiten entre los dos:

ella, porque bajó Dios,

y él, porque sube María. (217, vs.6-9).

......"

Aquí se introduce el tema de la Virgen María, a partir de una asombroso alabanza:

“......

pues el Vientre de Maria

es mucho mejor que el Cielo; (217, vs.22-23). ....."

Estos versos (22 -23), en los que se hace alusión a la maternidad de María tienen como antecedente al Breviario Romano, Responsorio de la Lección I de Maitines, en el Común de las Fiestas de N. Señora, que dice: "¡Oh Santa e inmaculada Virginidad!...A Aquél a quien los Cielos no podian encerrar, Tú lo llevaste en tu seno..... "(De La Cruz, 2004: 355). ${ }^{61}$

La 'competencia' en el villancico plantea diversas alegorías que destacan las virtudes de María; pero cabe destacar, como una primera respuesta al interrogante planteado en la hipótesis acerca de si hay en los villancicos de Sor Juana principios que postulan la igualdad de derechos entre mujeres y hombres, que en los versos que se transcriben a continuación, encontramos una primera cuestión importante $y$ es que la Tierra-María es el lugar de la Encarnación y su 'vientre inmaculado' es un elemento esencial del Dogma, porque sin Ella el Verbo no se hubiese hecho carne:

"La Tierra dice: -Pues más

\footnotetext{
${ }^{59}$ Ob., cit. Pág. 142.

${ }^{60}$ DE LA CRUZ, Sor Juana Inés. Obras Completas. Villancicos y Letras Sacras. Fondo de Cultura Económica, México, 2004. Págs. 3 y 4.

${ }^{61}$ Op., cit. Pág. 355.
} 


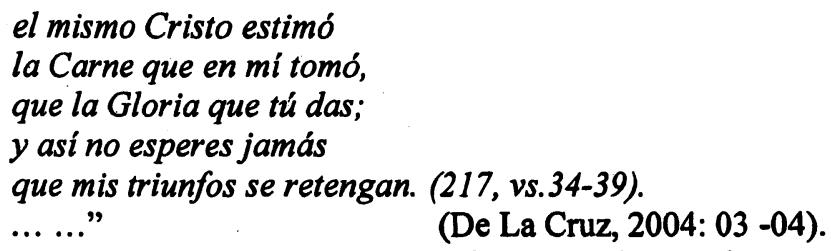

Consecuentemente, en este villancico se puede apreciar por una parte, cómo Sor Juana, a partir de la divinización de una acción concreta y profana como es una 'competencia' desarrolla un tema dogmático, la jerarquía de María y que lo hace utilizando términos simples y sencillos. Por otra, que expone su punto de vista acerca de la importancia de la Virgen como madre de Jesucristo, en razón de que lo impuro, la materia exterior a la idealización divinạ, que se localiza en la tierra (femenino), se transforma por la maternidad divina, en lo inmaculado (masculino).

En el Villancico 223 (VII del Tercero Nocturno 62) ${ }^{63}$, otra cuestión sobresaliente, que Sor Juana reitera soslayada, es la que aplica a la Virgen María por medio de una figura retórica: la sinécdoque. Y dice:

"Si a los tropos la acomodo,

ha ejercitado en el arte

el sinécdoque, de modo

que eligió la mejor parte

y la tomó por el todo.(223, vs.38-42).

.....". (De La Cruz, 2004: 12 -14).

Méndez Plancarte ${ }^{64}$, sefiala:"El sinécdoque (hoy femenino) es "tomar la parte por el todo" y "María eligió la mejor parte" (S. Lucas X, 42), que es Dios o "el Todo". (De La Cruz, 2004: 12).

Recurriendo a la explicación anterior, se interpreta que en los versos que mencionan el 'vientre inmaculado' de María, esa parte de su cuerpo es una sinécdoque, que la transforma en Todo. También, que al ser coronada por el Cielo lo que sobresale es una sinécdoque, la Cabeza, otra parte de su cuerpo, que es 'coronada con Estrellas'.

Lo expuesto nos lleva a inferir que el ascenso al Cielo convierte a María en 'Reina' y de esa manera Sor Juana la instala 'junto' con la Trinidad (Padre, Hijo y Espíritu Santo), que son las figuras masculinas que jerárquicamente se sitúan por encima de ella.

En el Villancico 219 (III de la Asunción de 16769) ${ }^{65}$, Sor Juana presenta a María como a una mujer asombrosa, que puede transformarse en doctora de teología.

"La SOBERANA Doctora

de las Escuelas divinas,

de quien los Angeles todos

${ }^{63}$ Op., cit. Págs. 12 a 14

${ }^{64}$ Op., cit. Pág.12.

${ }^{65}$ Op., cit. Pág.6. 
deprenden sabiduria, por ser quien inteligencia

mejor de Dios participa,

a leer la suprema sube

Cátedra de Teología. (219, vs.1-8).

...... (De La Cruz, 2004: 06). música:

En el Villancico 220 (IV del Segundo Nocturno) ${ }^{66}$, la presenta como maestra de

"Hoy la Maestra Divina,

de la Capilla Suprema

hace ostentación lucida

de su sin igual destreza:

......

en especies musicales

tiene tanta inteligencia,

que el contrapunto de Dios

dio en ella la mas Perfecta.(220,vs.7-10,23-26).

...... (De La Cruz, 2004: 07).

En el Villancico 223 (VII del Tercero Nocturno) ${ }^{67}$, como maestra de retórica:

"Para quien quisiere oir

o aprender a bien hablar,

$y$ lo quiere conseguir,

María sabe enseñar

el arte de bien decir. $(223$, vs.8-12).

...... (De La Cruz, 2004: 13).

En estos tres últimos villancicos se aprecian tres alegorías relacionadas con distintos campos del saber: el universitario en el que María se presenta a la cátedra de Teologia y es la primera; el musical en el que se distingue y en el arte de la retórica en el que 'sabe enseñar'.

Se piensa en consecuencia, que al destacar la capacidad académica y pedagógica de la Virgen María, como mujer, ubicándola en la posición de 'maestra' que puede impartir ensenaanzas, por una parte, Sor Juana transporta al contexto educativo - religioso cuestiones alegóricas y teológicas que son medulares en lo que refieren a la intencionalidad de los villancicos y por otra, labra su defensa del estudio y la enseñanza femeninos.

En el Villancico 221 (V del Segundo Nocturno ${ }^{68}$, Sor Juana presenta a María como una pastora. Para Octavio $\mathrm{Paz}^{69}$ este uno de los primeros villancicos de la autora y uno de los mejores logrados. Se trata de una paráfrasis del Cantar de los cantares y sus coplas están

\footnotetext{
${ }^{66}$ Op., cit. Pág.7.

${ }^{67}$ Op., cit. Pág.13.

${ }^{68}$ Op., cit. Pág.9.

69 PAZ, Octavio. Sor Juana Inés de la Cruz o Las Trampas de la Fe. Fondo de Cultura Económica. México.1992.Pág.429.
} 
organizadas en versos sencillos de seis sílabas y en el estribillo, se mezclan versos de distintas medidas.

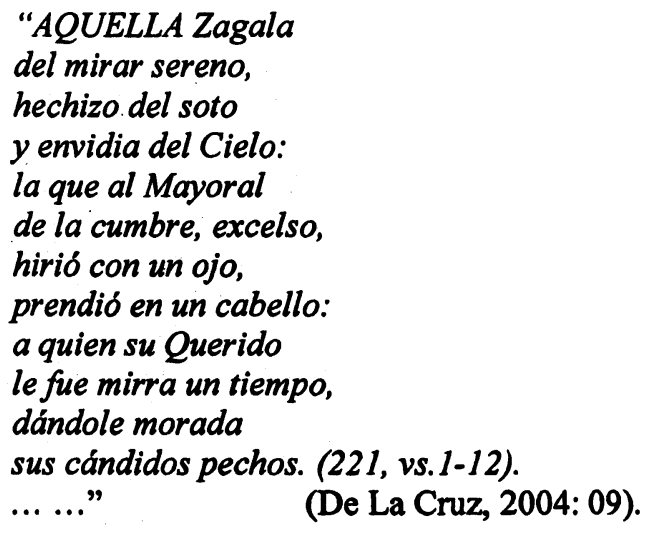

Dice Octavio Paz: "El estribillo convierte a Maria en un prodigioso cohete que asciende y se pierde en la altura. Ningún comentario substituye a la realidad esbelta de ese torbellino de palabras aéreas que se levanta de la página" $(\mathrm{Paz}, 1992: 429) .{ }^{70}$

"Estribillo

iAl monte, al monte, a la cumbre

Corred, volad, zagales,

Que se nos va Maria por los aires!

¿Corred, corred, volad aprisa, aprisa,

Que nos lleva robadas las almas y las vidas,

Y llevando en si misma nuestra riqueza,

Nos deja sin tesoros el Aldea! (221, vs.49-55)

......" (De La Cruz, 2004: 09).

El Villancico $222^{71}$ (VI del Segundo Nocturno), describe a María como a una caballera andante, regia en valentía, suma en su belleza y poseedora de una virtud incomparable.

“¡APARTEN! ¿Cómo, a quién digo? ¡Fuera, fuera! ¡Plaza, plaza,

Que va la jacarandina

como que No, sino al Alba!

5 iVaya de jacaranda, vaya, vaya, que si corre María con leves plantas, un corrido es lo mismo que una jácara!

Coplas

${ }^{70}$ Op., cit. Pág.429.

${ }^{71}$ DE LA CRUZ, Sor Juana Inés. Op., cit. Págs. 10 a 12.
40 La de quien tiembla el Infierno si su nombre se pronuncia, $\mathrm{y}$ dicen que las vigilias los mismos Reyes le ayunan; La que nos parió un León

45 con cuya rugiente furia al Dragón encantador puso en vergonzosa fuga; La más bizarra Guerrera 
¡Allá va, fuera, que sale la Valiente de aventuras,

Deshacedora de tuertos,

Destrozadora de injurias!

Lleva de rayos del Sol

resplandeciente armadura, de las Estrellas el yelmo,

15 los botines de la Luna; $y$ en un escudo luciente con que al Infierno deslumbra, un mote con letras de oro en que dice: Tota pulchra. La celebrada de hermosa y temida por sañuda, Bradamante en valentía, Angélica en hermosura; La que si desprende al aire

25 la siempre madeja rubia, tantos Roldanes la cercan cuantos cabellos la inundan; La que deshizo el encanto de aquella serpiente astuta, que con un conjuro a todos nos puso servil coyunda; La que venga los agravios, $y$ anula leyes injustas, asilo de los pupilos, y amparo de las viudas; La que libertó los presos de la cárcel donde nunca, a no intervenir su aliento, esperaran la soltura; que, entre la alentada turba, sirviendo al Imperio sacro mereció corona augusta;

La Paladina famosa que con esfuerzo e industria conquistó la Tierra Santa,

55 donde para siempre triunfa. Ésta, pues, que a puntapiés no hay demonio que la sufra, pues en mirando sus plantas, le vuelve las herraduras,

60 coronada de blasones y de hazañas que la ilustran, por no caber ya en la tierra, del mundo se nos afufa, y Andante de las Esferas, en una nueva aventura, halla el tesoro escondido que tantos andantes buscan, donde, con cierta virtud que la favorece oculta,

70 de vivir eternamente tiene manera segura. ¡Vaya muy enhorabuena, que será cosa muy justa, que no muera como todas

(De La Cruz, 2004: 10 - 12).

Cabe señalar aquí, que en estos dos villancicos, se puede apreciar que Sor Juana, por un lado: vincula el saber religioso con el conocimiento secular, relacionando las virtudes de la Virgen María con las de una pastora y una caballera andante; y por otro lado: estimo que a ese vinculo entre lo religioso y lo profano lo desarrolla a partir de distintos registros lingúísticos.

Por ejemplo, en el Villancico 221, Sor Juana elabora poéticamente el lenguaje heterodoxo del "Cantar de los cantares" con su entrecruce de lenguaje sexual y de amor místico; y en el Villancico 222 describe a la Virgen como una guerrera de la fe, utilizando el castellano y el latín. De esa manera, articula el discurso popular a lo divino. 


\section{La correspondencia de los villancicos de Sor Juana con la lírica tradicional}

Dice Alfonso Méndez Plancarte ${ }^{72}$, que el término 'villancico' se origina como un disminutivo de villano, aldeano o rústico y su cantar, su tañido o su baile característico o bien, a su imitación ya más o menos artificiosa. De allí, la vinculación de este género con la lírica tradicional, con el habla coloquial y la representación de los sectores populares de la sociedad. Agrega este autor, que en sus orígenes, su contenido había sido profano y que su interés principal era la representación del habla rústica. Dice también, que con posterioridad, se institucionalizaron como composiciones religiosas que se cantaban en las iglesias durante la Navidad y otras festividades religiosas y que hacia los años entre 1660 y 1750 se habían 'especializado', convirtiéndose en conjuntos o series de ocho a diez composiciones que trataban un tema religioso y que se representaban exclusivamente durante los Maitines de las fiestas litúrgicas. También, que una característica de esas series, es que finalizaban con una 'ensalada' en la que se representaban las múltiples voces de los sectores marginales de la sociedad.

En la última caracteristica señalada, se aprecia una correspondencia de los villancicos de Sor Juana, con sus origenes tradicionales, pues la Serie de Villancicos de la Asunción (1676) cierra con una 'Ensaladilla' en la que hablan 'los otros', la plebe en su doble connotación genérica, por una parte, 'los otros' como raza humana que se ubica por debajo de la Virgen y por otra, las clases sociales inferiores.

El Villancico 224 (VIII del Tercero Nocturno) ${ }^{73}$ es la Ensaladilla que se divide en tres registros vocales: la Reina, los Negros y los Indígenas.
"A LA aclamación festiva
de la jura de su Reina
se juntó la plebe humana
con la angélica nobleza.
$Y$ como Reina es de todos,
su coronación celebran,
$y$ con majestad de voces
dicen en canciones Regias (224, vs. 1-8).

.....". (De La Cruz, 2004: 14 - 18).

Como se ha señalado antes, los villancicos estaban dirigidos a grupos sociales heterogéneos que conformaban la estructura social de la colonia (españoles, criollos, indios y las castas), y es a ellos a quiénes se les da voz en estas canciones populares.

Asimismo, es Sor Juana, una voz femenina, la que emite diversas voces, que a la vez definen distintos niveles de comprensión teológica y situación social y racial, de ese modo ella otorga la posibilidad de que 'hablen' los representantes de las castas y estamentos sociales inferiores incluyendo a los marginados.

${ }^{72}$ DE LA CRUZ, Sor Juana Inés. Op., cit. Pág.XI.

${ }^{73}$ Op., cit. Pág. 14 a 18. 
Para concluir, siguiendo el orden de los interrogantes planteados al inicio, se expone como resultado de la lectura realizada, que los villancicos de Sor Juana se corresponden con la lírica tradicional, porque en ellos hay registros de las voces de los 'otros'; además que es posible apreciar en ellos, una divinización de temas que desde lo concreto proponen maneras simples de mirar los misterios divinos.

También, que Sor Juana recurre a este género para manifestar muchas de sus ideas teológicas, que de otra forma le estaban prohibidas, y que además, desde esta perspectiva realiza una acción política (personal), porque se vale de un género lírico, que componían los poetas de Nueva España, precisamente, para celebrar un orden social religioso y una ideología (patriarcal).

Y por último, que Sor Juana propicia con sus villancicos la enseñanza del catecismo y de las cuestiones que tenían relación con lo religioso porque explica al pueblo de manera simple, misterios teológicos que eran ininteligibles para la mayoría.

\section{Referencias bibliográficas:}

DE LA CRUZ, Juana Inés. Obras Completas. Tomo II, Fondo de Cultura Económica, México, 2004.

FRENK, Margit (ed).Villancicos, romances, ensaladas y otras canciones devotas de Fernán González Eslava. El Colegio de México. México.1989.

FRENK, Margit. Estudios sobre lírica antigua. Edición Castalia. España. 1978.

GLANZ, Margo. El discurso religioso y sus políticas. Fondo de Cultura Económica. México. 1995.

PAZ, Octavio. Sor Juana Inés de la Cruz o Las Trampas de la Fe. Fondo de Cultura Económica. México.1992.

SANCHEZ ROMERALO, Antonio. El Villancico. Gredos. España.1969.

WARDROPPER, Bruce W. Historia de la Poesía Lírica a lo Divino en la Cristiandad Occidental. Revista del Oriente. España. 1958.

\section{Sitios Web:}

www.cervantesvirtual.com. MARTINEZ SAN MIGUEL, Yolanda. Saberes Americanos: la constitución de una subjetividad colonial en los villancicos de Sor Juana.

Elsa Beatriz Grillo es Licenciada y Profesora en Enseñanza Media y Superior en Letras, egresada de la Facultad de Humanidades de la UNNE. Doctoranda en Letras de la Universidad del Salvador. Profesora Adjunta a cargo de Literatura Iberoamericana 1; Profesora Adjunta del "Seminario Taller de Literatura" y Auxiliar del "Taller de Compresión y Producción de Textos" de la Facultad de Humanidades de la UNNE. 